\title{
Genetic Determination of Tolerance to Lethal and Sublethal Copper Concentrations in Field Populations of Daphnia longispina
}

\author{
I. Lopes, ${ }^{1}$ D. J. Baird, ${ }^{2}$ R. Ribeiro ${ }^{1}$ \\ ${ }^{1}$ Departamento de Zoologia, Instituto do Ambiente e Vida, Universidade de Coimbra, Largo Marquês de Pombal, 3004-517 Coimbra, Portugal \\ ${ }^{2}$ Environment Group, Institute of Aquaculture, University of Stirling, Stirling, FK9 LA4, Scotland, United Kingdom
}

Received: 18 August 2002/Accepted: 7 June 2003

\begin{abstract}
In order to study the effects of environmental pollution on the genetic diversity of natural populations, two field populations of the cladoceran Daphnia longispina were sampled: one in a reference site (uncontaminated) and the other in a site historically stressed with acid mine drainage (AMD). Five hypotheses were formulated: (1) the stressed population presents a higher tolerance to lethal levels of copper than the reference population, (2) differences in tolerance to lethal levels, observed between the two populations, are due to the loss of sensitive lineages, (3) differences in tolerance to lethal levels of copper between the two populations are due to the appearance of new genotypes, (4) the acquisition of tolerance to lethal levels of copper involved changes in life-history patterns and fitness costs under optimal conditions, and (5) historical contamination by AMD resulted in tolerance differences to sublethal levels between populations, within categories similarly tolerant to lethality, specifically, lineages with similar tolerance to lethal levels from both populations show differences in tolerance to sublethal levels, the stressed population being more tolerant to sublethal levels of contamination than the reference population. Over 125 acclimated cloned lineages, from each population, were exposed to different copper concentrations for 24 hours. At the end of each assay, mortality and feeding inhibition were monitored. Life-cycle traits under optimal conditions were also monitored (time to first brood, number of neonates per brood, inter-brood time, body length, and ingested algae). At lethal levels of copper, significant differences were found in the frequency of sensitive lineages between the two populations. The stressed population did not include the most sensitive lineages, though the most tolerant ones were also present in the reference population. Thus, the hypothesis of presence of new genotypes in the stressed population resulting in an overall increase tolerance of the population at lethal levels was rejected. Changes in life-history patterns were detected, though they were not fully consistent with predictions of life-history theory. Furthermore, these changes in life-history patterns did not involve fitness costs. The fifth hypothesis was rejected since, at sublethal levels of copper, no significant differences were found between the
\end{abstract}

Correspondence to: R. Ribeiro; email: rui.ribeiro@zoo.uc.pt feeding inhibitions of similarly lethal tolerant lineages of the two populations, with only one exception. Therefore, the present study further confirmed the genetic erosion hypothesis and gave further support to the incorporation of genetic diversity measurements into risk assessments.

Natural populations usually hold a large number of genetically different individuals, which, consequently, will respond differently to environmental changes. When a toxicant enters the environment it will affect the population by stressing individuals, which can respond to stress by tolerating it, avoiding it, or dying. Latter two responses will cause an increase in the overall tolerance of the population, due to the replacement of sensitive (the ones who do not reproduce) individuals by tolerant ones (the reproducing remnants). If the population persists in a toxic environment, then, three kinds of responses, at the individual level, could be responsible for such phenomena: organisms can enhance physiological/biochemical tolerance mechanisms (e.g., increased enzyme activities, production of metal binding proteins), activate alternative genetic programs during development (developmental conversion), and life-cycle traits can be modified in order to avoid contact with the stressor or as a result of costs involved in stress tolerance (Maltby et al. 1987; Hoffmann and Parsons 1994; Forbes and Calow 1997). The two former situations are associated with phenotypic plasticity and will not alter the frequency of genotypes in the population, specifically, the environment only alters the phenotypic expression of the genotypes. The modification of life-history patterns may involve both phenotypic plasticity (e.g., through the displacement of energy allocation) (Stibor 1992; Barata et al. 1998) and/or changes in the genotype frequencies (Reede 1995).

At the population level, tolerance can be acquired through natural selection acting at the individual level. In this case, the stressor will act as a selective force by eliminating the least fit genotypes (for instance, genotypes producing lower levels of metallothionein-like proteins could show a lower reproductive output) and, thus, causing a shift in the overall mean of a specific trait in the population. This shift can occur only as a 
result of a change in population genotype frequencies and/or through the appearance and spread of a new gene (through mutation) or a new combination of genes (through sexual recombination). In both situations, tolerance acquisition will depend on the amount of genetic variability available at that time in the population.

Natural selection tends to maximize survivorship (s) and fecundity (n) and minimize developmental time (t); stressors will reduce $s$ and $n$ and increase $t$. If adaptation occurs then one life-cycle component may be compensated for by an increase in another one, for example reduced adult survival can be compensated for by and increase in fecundity. Such changes in life-history patterns depend not only on the stressor but also on the amount of genetic variation in the population, on trade-offs between life-cycle traits and on matings with non-tolerant individuals (Falconer 1996). These shifts can disappear with the stressor, indicating that increased tolerance resulted from acclimatization phenomena, or they can persist even after removing the stressor, indicating that mechanisms responsible for increased tolerance were genetically determined (Lam 1999; Reinecke et al. 1999; Spurgeon and Hopkin 2000). Adaptation to stressful environments has been widely studied in plants (Macnair 1997; Nordal et al. 1999; Monni et al. 2000) and, less commonly, in animals (Klerks and Weis 1987). Donker et al. (1993) compared life-history traits between isopods living in metal contaminated and reference areas, and found that females from the contaminated area started to reproduce earlier, at a lower weight and producing fewer young per female, confirming the presence of trade-offs between lifecycle traits caused by stressful conditions.

The present study was designed to clarify the processes underlying an eventual increased tolerance to metal contamination in Daphnia longispina field populations historically stressed by acid mine drainage (AMD) in comparison to reference populations. Five hypotheses were formulated and tested: (1) a historically stressed population shows a higher tolerance at lethal levels in comparison to a reference population, (2) increased tolerance at lethal levels of the stressed population is due to the elimination of the most sensitive genotypes from the original population, (3) such increased overall tolerance at lethal levels is due to the appearance of new genotypes with an higher tolerance than those from the original population, (4) lethal tolerance mechanisms acquired by tolerant lineages involved changes in life-history patterns and fitness costs under optimal conditions, and (5) historical contamination by AMD resulted in differences in tolerance to sublethal levels between populations, within categories similarly tolerant to lethality, specifically, lineages with similar tolerance at lethal levels from both populations show differences in tolerance at sublethal levels, the stressed population being more tolerant at sublethal levels of contamination than the reference population.

\section{Materials and Methods}

\section{Study Site}

An aquatic system impacted with acid mine drainage (AMD), from an abandoned cupric-pyrite mine (S. Domingos: active from 1868 to
1967), was selected for the development of this study. Though ore exploitation ended more than thirty years ago, the continuous oxidation of abandoned mine tailings produces a highly acidic effluent $(\mathrm{pH} \cong 2.1)$, contaminated with heavy metals ( $\mathrm{Fe}, \mathrm{Al}, \mathrm{Zn}, \mathrm{Cu}, \mathrm{Mn}, \mathrm{Co}$, $\mathrm{Ni}, \mathrm{Cd}, \mathrm{Pb}, \mathrm{Cr}$, As; in decreasing order, see Lopes et al. 1999a). This untreated effluent currently discharges into the Chança River reservoir (SE Portugal) within the Guadiana River basin (Figure 1).

This aquatic system is ideal for the study of adaptations occurring in field populations exposed to historical chemical stress, for three reasons: (1) the source of contamination is isolated and identified; no agriculture or industrial activities are present and there is no urban runoff; (2) reference sites free of metal mining contamination exist close to the contaminated area; (3) extensive data on the biology, ecology, and water chemistry of the systems are available (Pereira $e t$ al. 1995, 1999, 2000; Ribeiro et al. 1995; Lopes et al. 1999a, 1999b; Castro et al. 2003).

\section{Field Populations}

Two populations of the cladoceran D. longispina O.F. Müller were sampled in the field: population $\mathrm{R}$ at a reference site located upstream of the contamination source (site R: pH 7.35, $236 \mu \mathrm{S} / \mathrm{cm}$, D.O. 9.7 $\mathrm{mg} / \mathrm{L}$ ), and population I at a site historically impacted with acid mine drainage, located below the confluence of the acidic effluent with the Chança reservoir (site I: pH 6.37, $295 \mu \mathrm{S} / \mathrm{cm}$, D.O. $9.2 \mathrm{mg} / \mathrm{L}$ ) (Figure 1). On Table 1 are depicted the hardness and copper concentrations of previously collected waters samples with $\mathrm{pH}$ and conductivity values close to those measured at sites $\mathrm{R}$ and I, at the time of dafnids' collection. The collection of dafnids followed the procedure described by Lopes et al. (1999b). At each site (reference and impacted), only one egg-bearing female was isolated from each net trawl. Net trawls were about $2 \mathrm{~m}$ apart from each other, aiming to maximize the representativeness of the sampled population. Organisms were subsequently taken to the laboratory, and, using a dissecting microscope, each egg-bearing female was transferred to a culture beaker filled with $50-\mu \mathrm{m}$ filtered site water. From the reference and the stressed populations, 136 and 129 egg-bearing females were isolated, respectively. Juveniles born the day after collection, from field-collected females were maintained in the laboratory, and acclimated to controlled conditions: $25 \pm 1{ }^{\circ} \mathrm{C}$ with a photoperiod of 14:10 h L:D in American Society for Testing and Materials (ASTM) hardwater medium (ASTM 1994), with the addition of vitamins and the organic additive Marinure 25 (Baird et al. 1989), and fed daily with the green algae Pseudokirchneriella subcapitata (formerly known by Selenastrum capricornutum) $\left(3 \times 10^{5}\right.$ cells $\left./ \mathrm{mL} / \mathrm{d}\right)$, obtained from the Caroline Biological Supply Company (Burlington, NC, USA). Each of the 265 lineages were maintained, by asexual reproduction (cloning), under these controlled conditions for, at least, 15 generations prior to assays (only neonates from third and fourth broods were isolated to maintain laboratory cultures).

For both populations, the body length and the number of neonates in the brood released at the laboratory, the day after collection, were assessed for 50 randomly subsampled egg-bearing females (nonacclimated) collected in each site. The individual relative energy allocation for reproduction, specifically, individual relative investment on reproduction (number of neonates released per female divided by the respective body length), was also computed for each population.

Conductivity (WTW LF92 conductivity meter), pH (WTW 537 pH meter), and dissolved oxygen (WTW OXI92 oxygen meter) were measured at each sampling site and at the beginning and at the end of each assay. 


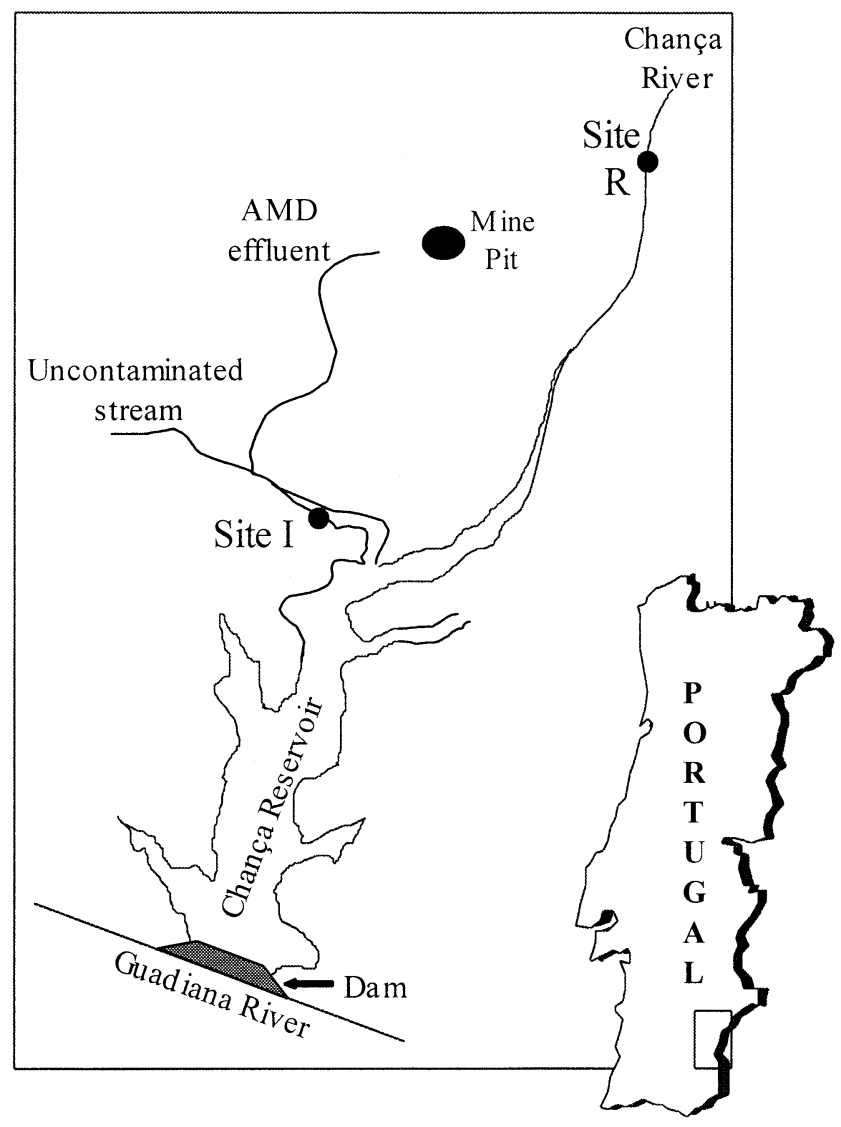

Fig. 1. Scheme of the aquatic system of S. Domingos impacted with acid mine drainage. Sampling sites are indicated as R and I for the reference and the impacted field populations of Daphnia longispina, respectively.

Table 1. Hardness and copper concentrations of previously collected water samples with $\mathrm{pH}$ and conductivity values close to those measured at sites R and I, at the time of dafnids' collection

\begin{tabular}{lcc}
\hline & Site $\mathrm{R}$ & Site I \\
\hline $\mathrm{pH}$ & 7.35 & 6.37 \\
Conductivity $(\mu \mathrm{S} / \mathrm{cm})$ & 236 & 295 \\
Previous $\mathrm{pH}$ & 7.42 & 7.15 \\
Previous conductivity & 271 & 312 \\
Previous hardness $\left(\mathrm{mgCaCO}_{3} / \mathrm{L}\right)$ & 89.7 & 85.7 \\
Previous copper concentration $(\mathrm{mg} / \mathrm{L})$ & 0.027 & 1.7 \\
\hline
\end{tabular}

\section{Tolerance at Lethal and Sublethal Levels of Copper}

To study tolerance to lethal levels of copper, fully acclimated organisms were exposed to different copper concentrations $(60,80,150$, 250 , and $350 \mu \mathrm{g} / \mathrm{L}$ of $\mathrm{Cu}$ ), prepared by dissolving copper sulfate (supplied by Merck, Germany) in nano-pure water $(80 \mathrm{mg} / \mathrm{L}$ of $\mathrm{Cu}$ at $25 \pm 1{ }^{\circ} \mathrm{C}$ ) and then diluted with ASTM hardwater. Metal analyses were considered unnecessary since no concentration-effect relationships were intended to be established, but solely the comparison of relative sensitivities between cloned lineages and between populations. Furthermore, it was already shown that differences between nominal and actual concentrations of copper sulfate in nano-pure water and diluted with ASTM hardwater were lower than 10\% (Barata et al. 1998, 2000). Specifically, Barata et al. (1998) obtained copper concentrations ranging from 1.5 to $400 \mu \mathrm{S} / \mathrm{cm}$ (the copper concentrations used in the present study were within this range) and found that differences between nominal and actual concentrations after $24 \mathrm{~h}$ (equal to the one used in the present study) were lower than $10 \%$.

All 265 lineages were exposed to concentrations of 80 and $150 \mu \mathrm{g} / \mathrm{L}$ and to the control water (ASTM hardwater medium). The most sensitive lineages (presenting some mortality at $80 \mu \mathrm{g} / \mathrm{L}$ ) were subsequently exposed to a lower concentration $(60 \mu \mathrm{g} / \mathrm{L})$ and the most tolerant ones (no mortality at $150 \mu \mathrm{g} / \mathrm{L}$ ) to higher concentrations (250 and $350 \mu \mathrm{g} / \mathrm{L}$ ). The assays were performed by introducing five 4-d-old juveniles (younger organisms would make difficult the determination of feeding inhibition) in $15-\mathrm{mL}$ polypropylene tubes, containing 12 $\mathrm{mL}$ of copper solution, with no replication per lineage. Assays were carried out in the dark (to minimize algal growth) at $25 \pm 1{ }^{\circ} \mathrm{C}$, for $24 \mathrm{~h}$. In the beginning of each assay, organisms were fed with the green algae $P$. subcapitata in a concentration of $3 \times 10^{5}$ cells $/ \mathrm{mL}$. Blanks (tubes with algae but without organisms) were performed simultaneously to assure that algal concentration did not changed during the assay (all $t$-tests: $p \geq 0.56, t_{6}=0.6$ ). At the end of the assay mortality and feeding inhibition were monitored for each lineage. To assess feeding, organisms were removed from the test tubes and the test solutions were centrifuged for $10 \mathrm{~min}$ at $4500 \mathrm{rpm}$; the resulting pellet (noningested algae) was then resuspended in $1 \mathrm{~mL}$ of the supernatant. These samples were then conserved with Lugol, to avoid algal growth, and, then counted in a Newbauer chamber under a microscope. The number of algae counted in the Newbauer chamber was then subtracted to the initial number of cells to compute ingested algae. Feeding inhibition, as the sublethal evaluation endpoint, was calculated by subtracting the ingested algae in the NOEC for lethality (i.e., the highest concentration where no mortality was observed) from the ingested algae in the control water, and, then divided by the number of cells ingested in the control and presented as percentage.

Lineages were ranked in six categories according to their tolerance to lethal levels of copper: Extremely Sensitive (ES), Very Sensitive (VS), Sensitive (S), Tolerant (T), Very Tolerant (VT), and Extremely Tolerant (ET) lineages with a NOEC lower than 60 (ES), and equal to 60 (VS), to $80(\mathrm{~S})$, to 150 (T), to 250 (VT), and to $350 \mu \mathrm{g} / \mathrm{L}$ (ET), respectively.

\section{Life-History Patterns}

To investigate whether the acquisition of tolerance to copper involved changes in life-history patterns and fitness costs, some life-cycle traits were monitored in fully acclimated organisms under optimal conditions. The life-cycle of neonates (6 to 24-h old) from the third brood was monitored in a 16-d experiment: time to the first brood, number of neonates per brood, time inter-broods, body length of females after releasing the fourth brood, and, in a 24-h experiment in the dark, ingested algae. During the former experiment, assayed organisms were maintained in the same conditions as they were in laboratory cultures (see above), until all the fourth broods were released (16 d).

\section{Data Analysis}

The comparison of mortality curves between populations was made with the nonparametric Mann-Whitney's U-test. Median lethal concentrations values and the respective 95\% confidence limits were calculated by probit analysis, using the program Probit Analysis 2.2 (developed by A. Nogueira, Coimbra, Portugal, unpublished). Lifecycle traits were compared using the Student's t-test (clutch size, length and ingested algae) and with the nonparametric Mann-Whitney's-U test (time to first brood). Comparisons of ingested algae 
between categories and between populations were performed with two-way ANOVA followed by pairwise Student's $t$-tests when significant differences were observed. Differences between regression coefficients and elevations in life-history traits relationships were tested (Gad and Weil 1982; Zar 1996). Coefficients of variation (CVs) were calculated for clutch size, body length, and ingested algae to quantify and compare plasticity (i.e., breath of response) of these parameters, between the two populations. Homogeneity between coefficients of variation was analyzed using the Miller and Feltz's equation (Zar 1996). All analyses, except for homogeneity between CVs, were performed using the computer program Statistica for Windows 4.3 (StatSoft Inc., Aurora, CO, USA).

\section{Results}

Females collected at the reference site were smaller (average \pm $\mathrm{SD}: 1.61 \pm 0.10$ versus $1.78 \pm 0.10 \mathrm{~mm}$; $t$-test: $p<10^{-6}$, $\left.t_{98}=8.63\right)$ and released less neonates than those collected at the impacted site (average $\pm \mathrm{SD}: 4.3 \pm 1.3$ versus $5.4 \pm 2.1$ neonates/female; $t$-test: $p<10^{-7}, t_{239}=5.19$ ). No significant differences were observed in the coefficients of variation of body length (6 versus 6\%; Miller and Feltz: $p>0.05)$ and number of released neonates (31 versus 39\%; Miller and Feltz: $p>0.05)$. Population $\mathrm{R}$ exhibited a lower relative investment on reproduction than population I (average $\pm \mathrm{SD}: 2.5 \pm 0.7$ versus $3.1 \pm 1.3$ neonates $/ \mathrm{mm}$; $t$-test: $p=0.004, t_{98}=2.92$ ).

Physical parameters presented only small variations during bioassays; dissolved oxygen was always above $8.2 \mathrm{mg} / \mathrm{L}, \mathrm{pH}$ values were close to neutrality (the lowest value was 7.8) and conductivity values ranged from 567 (in ASTM hardwater) to $583 \mu \mathrm{S} / \mathrm{cm}$ (in the highest copper concentration). The highest variations registered for each parameter in each assay were 0.2 $\mathrm{mg} / \mathrm{L}, 0.1$ and $3 \mu \mathrm{S} / \mathrm{cm}$, respectively.

\section{Tolerance to Lethal Levels of Copper}

The dafnids from population $\mathrm{R}$ exhibited a lower tolerance to lethal levels of copper than the ones from population I, presenting a two-fold lower median lethal concentration value at $24 \mathrm{~h}$ (and respective 95\% confidence limits): 104.6 (40.6-242.2) and 242.2 (227.7- 257.8) $\mu \mathrm{g} / \mathrm{L}$. At $80 \mu \mathrm{g} / \mathrm{L}$, the population I exhibited no mortality, while $54 \%$ of organisms from population R died. Comparing mortality between the two populations exposed to 150 , 250 , and $350 \mu \mathrm{g} / \mathrm{L}$ of copper, the dafnids from population $\mathrm{R}$ always presented a significantly higher mortality (U-tests: $p<$ $10^{-6}, \mathrm{U}_{136,129}=2559 ; p<10^{-6}, \mathrm{U}_{128,126}=3351$; and $p<10^{-3}$, $\mathrm{U}_{124,74}=3591$, respectively). Furthermore, Extremely Sensitive (ES) and Very Sensitive (VS) lineages (NOEC lower than and equal to $60 \mu \mathrm{g} / \mathrm{L}$, respectively) were present only in the population $\mathrm{R}$ (Figure 2). Tolerant lineages (T) were the most frequent in the population I, representing more than $80 \%$ of the total lineages (Figure 2). Very and Extremely Tolerant lineages (VT and ET) were present in both populations R and I, with similar frequencies (below 20\%) (Figure 2).

\section{Life-History Patterns}

At the end of the 16-day experiment, under optimal conditions with fully-acclimated organisms, less than $10 \%$ of mortality occurred in both populations. No differences between the two populations were observed in the time to first reproduction; both populations releasing the first brood around the ninth day (U-test: $p=0.36, \mathrm{U}_{132,127}=7727$ ) (Figure 3 ). The number of neonates released in the first and second broods were significantly higher in population I ( $t$-tests: $p<10^{-8}, t_{257}=5.65$; and $p<10^{-13}, t_{255}=7.52$, respectively) (Figure 3 ). No significant differences were observed in the number of juveniles released in third and fourth broods ( $t$-tests: $p=0.165$, $t_{248}=1.58$; and $p=0.265, t_{246}=1.12$, respectively) (Figure 3 ). At the end of the assay, the dafnids from population had released more neonates (average $\pm \mathrm{SD}: 36.3 \pm 9.6$ versus $32.8 \pm 11.5$ total neonates per female; $t$-test: $p=0.03, t_{257}=$ 2.14) and females were on average larger than the ones from population $\mathrm{R}$ (average $\pm \mathrm{SD}: 2.13 \pm 0.09$ versus $2.03 \pm 0.10$ mm; $t$-test: $p<10^{-6}, t_{246}=8.12$ ) (Figure 4). The dafnids from population $\mathrm{R}$ presented a significantly higher variability in the number of neonates released per female than the ones from population I (CVs: 35 versus 27\%; Miller and Feltz: $p<0.02$ ). No significant differences in the variability of body length values between the two populations were observed (CVs: 4 versus 5\%; Miller and Feltz: $p>0.50$ ).

The individual relative energy allocation for reproduction, i.e., individual relative investment in reproduction (number of neonates released per female divided by the respective body length) was also computed for each population. Dafnids from population $\mathrm{R}$ exhibited a similar individual relative investment in reproduction compared with the ones from population I (average $\pm \mathrm{SD}: 17.1 \pm 4.2$ versus $17.9 \pm 3.2$ neonates $/ \mathrm{mm}$; $t$-test: $\left.p=0.50, t_{246}=0.68\right)$.

Feeding assays under optimal conditions showed that the dafnids from population I ingested significantly more algae than the ones from population R (average \pm SD: $2.8 \times 10^{5} \pm 4.9 \times$ $10^{4}, n=134$, and $2.7 \times 10^{5} \pm 3.5 \times 10^{4}$ ingested algae per five juveniles, $n=129$ lineages; $t$-test: $p=0.006, t_{261}=2.78$ ). Significant differences were observed in the variability of ingested algae; population $\mathrm{R}$ exhibited a higher variability than the population I (CVs: 18 and 13\%; Miller and Feltz: $p<0.001$ ).

Correlations between body length and total number of neonates per female during the 16-day experiment, under optimal conditions, were significant in both populations. No significant differences were observed between slopes ( $t$-test: $p>0.05$, $\left.t_{246}=1.76\right)$, and elevations ( $t$-test: $\left.p>0.05, t_{245}=0.147\right)$ of regression equations from the two populations. The common equation is noted in Figure 4.

Results from these two experiments (24-hour, in the dark, and 16-day long) under optimal conditions revealed that, within populations, no significant differences were observed when comparing ingested algae, total neonates per female and body lengths between categories of similar tolerance to lethality (six one-way ANOVAs: $p \geq 0.38, \mathrm{~F}_{2-4,246-261} \geq 0.04$ ). Within categories, the comparison between populations revealed that category $\mathrm{T}$ from population $\mathrm{I}$ ate more than the corresponding category from population $\mathrm{R}$ ( $t$-test: $p=0.005$, $t_{113}=2.86$ ). Significant differences between categories were also found in body length values; categories $\mathrm{S}$ and $\mathrm{T}$ from population I being bigger than corresponding categories from population $\mathrm{R}$ (two $t$-tests: $p \leq 0.002, t_{25-104} \geq 3.54$ ). As lineages VS were the most frequent in population $\mathrm{R}$ and lineages $\mathrm{T}$ in population $\mathrm{I}$, ingested algae, total neonates per female and the body lengths were compared between these two 


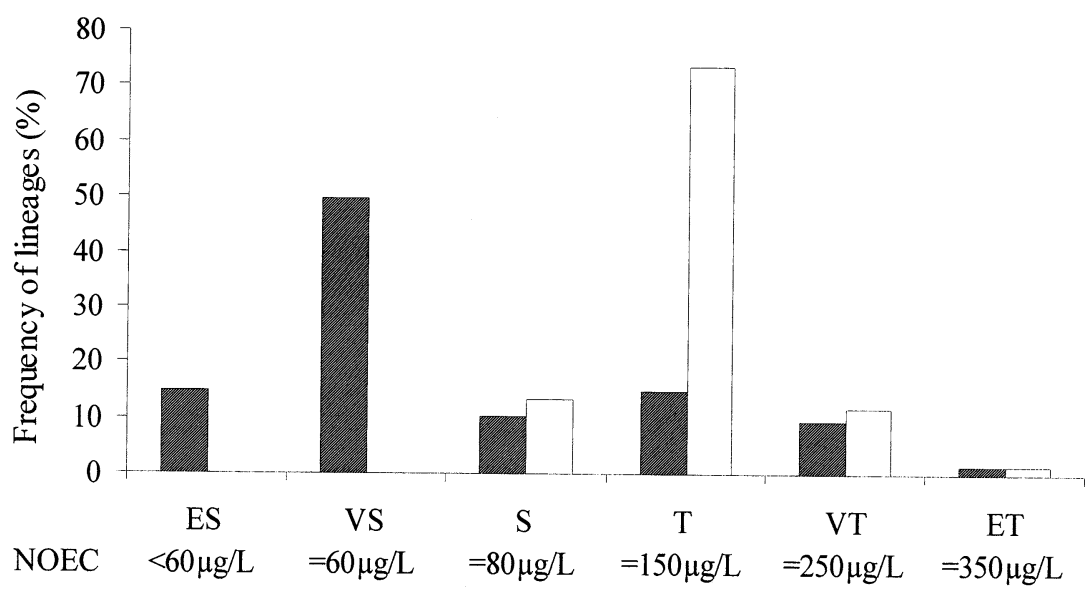

Categories of tolerance to lethal levels of $\mathrm{Cu}$

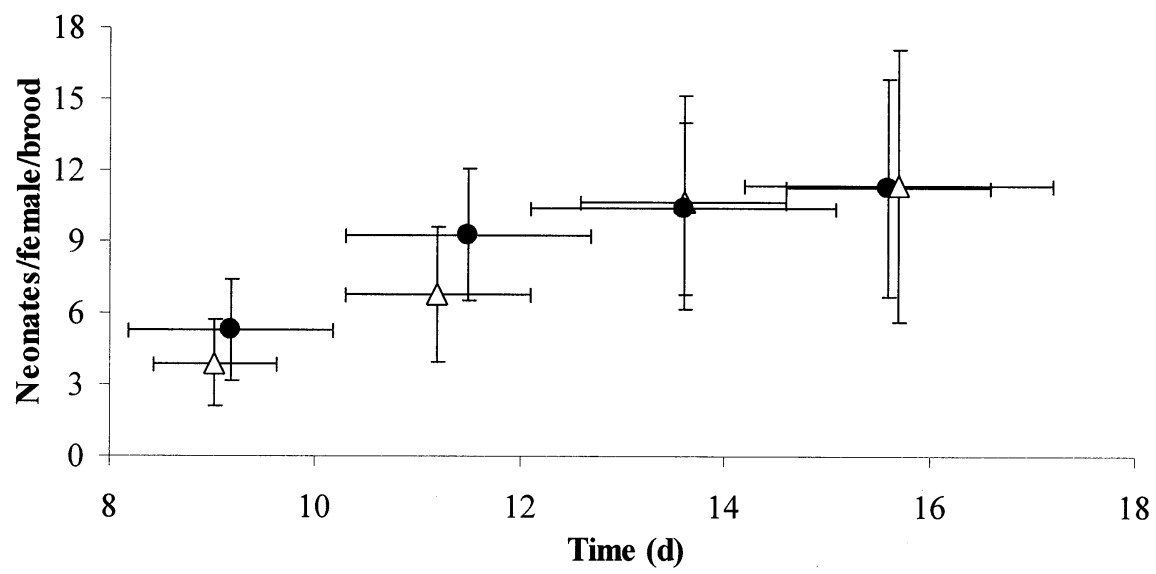

Fig. 2. Frequencies of Extremely Sensitive (ES), Very Sensitive (VS), Sensitive (S), Tolerant (T), Very Tolerant (VT), and Extremely Tolerant (ET) lineages of fully acclimated Daphnia longispina, from populations $\mathrm{R}$ (solid bars) and I (open bars).
Fig. 3. Number of neonates released per female per brood (average \pm SD) of fully acclimated Daphnia longispina during the 16-day experiment under optimal conditions. Circles and triangles represent populations I and $\mathrm{R}$, respectively.

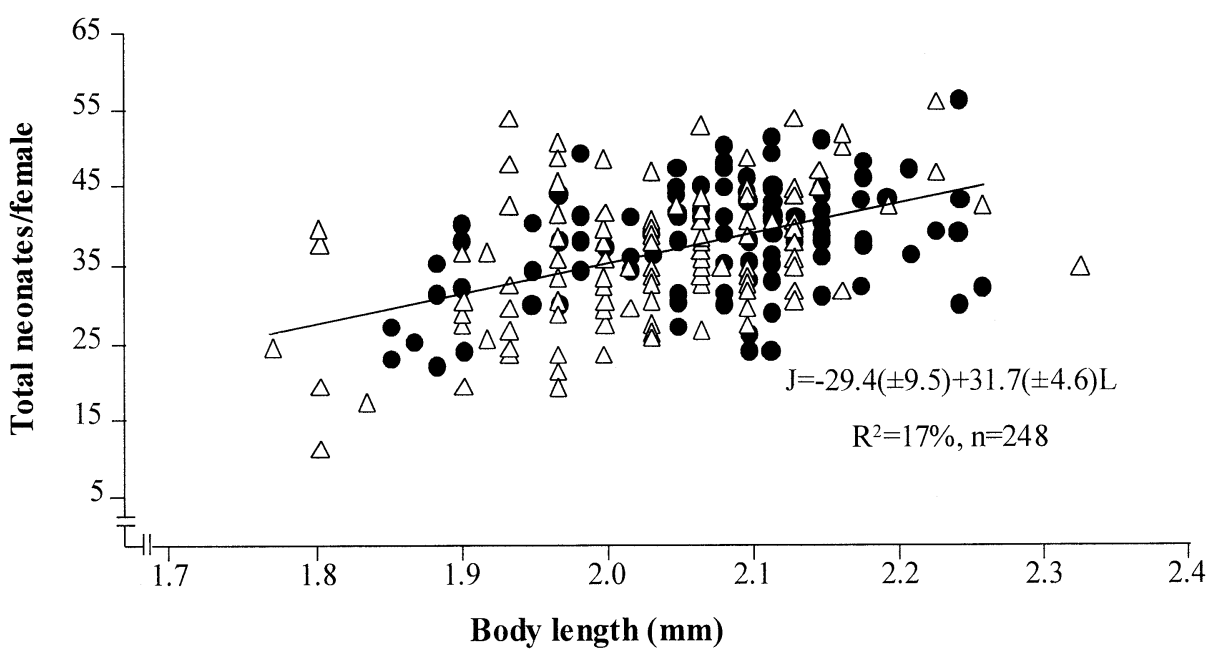

Fig. 4. The common regression equation between total neonates released per fully acclimated Daphnia longispina female $(\mathrm{J})$ and respective body length (L). SE are presented inside brackets. Circles and triangles represent the populations I and R, respectively. categories. For the three parameters, significant differences were observed between the two categories; lineages $\mathrm{T}$ from population I ate more, released more neonates and were larger than lineages VS from population $\mathrm{R}$ (three $t$-tests: $p \leq 0.05$, $t_{144-160} \geq 1.80$ ).

\section{Tolerance to Sublethal Levels of Copper}

Significant differences in the number of ingested algae between populations and between categories were found (two-way ANOVA: $p=0.013, \mathrm{~F}_{160}=6.30$ and $p=0.0018, \mathrm{~F}_{160}=6.56$, 
respectively). Ingested algae were then compared between populations for each category exposed to ASTM (control) and to the respective NOEC. When exposed to the respective NOEC, significant differences were never found, except for the category VT, where organisms from population $\mathrm{R}$ ate more than organisms from population I (average \pm SD: $2.5 \times 10^{5} \pm$ $3.1 \times 10^{4}$ versus $2.0 \times 10^{5} \pm 4.9 \times 10^{4}$ ingested algae per five juveniles; $t$-test: $p=0.013, t_{24}=2.1$ ). This means that, though the NOEC for lethality inhibited feeding in the category VT of both populations, lineages VT from population R were more tolerant at sublethal levels of copper than lineages with similar tolerance to lethal levels from population I. The NOECs for lethality presented, in all cases, sublethal effects because significant differences, for all categories, were found between ingested algae in controls and in the respective NOECs for lethality (Figure 5). The comparison of lineages VT was performed independently for each population because, as explained above, significant differences in feeding inhibition were found between populations. For category VS, only lineages from population $\mathrm{R}$ were tested for significance, since no lineages VS occurred in population I (six $t$-tests: $p \leq 0.02$, $t_{6-225} \geq 2.39$ ) (Figure 5).

\section{Discussion}

\section{Tolerance to Lethal Levels of Copper}

The first hypothesis of this study investigated differences in genetically determined tolerance to lethal levels of copper between reference and historically stressed populations. Previous studies have reported that populations exposed to sublethal levels of a toxicant can develop tolerance to that particular toxicant (Bodar et al. 1990; Groenendjik et al. 1999; Guillemaud et al. 1999), which acts as a selective pressure eliminating the least fit organisms (Hoffman and Parsons 1994). Accordingly to this, it would be expected that population I, historically exposed to heavy metal contamination, would present a higher tolerance to copper relative to the reference population. Results obtained by exposing all lineages to 80, 150,250 , and $350 \mu \mathrm{g} / \mathrm{L}$ of $\mathrm{Cu}$ corroborated this hypothesis, since a significantly lower mortality was always registered in the population I relative to population R (Figure 2). Thus, it was demonstrated that the population I presented a higher genetically determined tolerance to copper as a result of past exposure to heavy metals-enriched waters in the field, since all organisms were fully acclimated in the laboratory, under the same controlled conditions, to eliminate maternal and environmental effects (Barata and Baird 1998, Lam 1999). Genetically determined tolerance to lethal levels in a population can result from the appearance of new genotypes (through sexual recombination and, eventually, mutations) or through a shift in population genotype frequencies. The second and third objectives of this study intended to distinguish which process occurred in population I. In the former case, it would be expected to observe Extremely Tolerant lineages in population I, but not in population R, which was not the case: tolerant lineages (T, VT, and ET) were present in both populations. Furthermore, Extremely and Very Sensitive lineages were only present in population R. Thus, results of tolerance to lethal levels of copper demonstrated that a change in the frequencies of lineages in population I occurred, specifically, all lineages were present in the original population, but, with the introduction of chemical contamination, sensitive lineages were eliminated at site I. Tolerant lineages were able to survive and reproduce in the stressful conditions due to differences in genetically determined physiological mechanisms.

\section{Life-History Patterns and Fitness Costs}

The fourth objective of this study was to determine if changes in life-history patterns were involved with the acquisition of tolerance to lethal levels of copper, as well as fitness costs. Life-history theory predicts that stressful environments inducing reduced survival and reproduction will select for early maturation and increased reproductive effort per clutch (Maltby et al. 1987; Van Straalen 1994; Forbes and Calow 1997). This prediction was confirmed in laboratory by several authors (Donker et al. 1993; Posthuma et al. 1993; Teschner 1995). For example, Posthuma et al. (1993) compared lifehistory traits between a reference and a metal-tolerant population of isopods and observed a reduction in age at first reproduction as well as an increase in fertility in the tolerant population. Therefore, based in these evidences, it was expected that population I, historically exposed to stressful conditions leading to reduce adult survival, would show modifications in life-history traits under optimal conditions, relatively to population R. Consistent with life-history predictions, population I presented a higher clutch size per female at the end of the assay, relative to populations R. Differences in clutch size were significantly higher in the first and second brood, and no significant differences occurred in the third and fourth broods. Similar results were obtained when comparing recently fieldcollected females: population I released more neonates than population R. Other results obtained in this study are not fully consistent with those life-history theoretical predictions: no significant differences in time to release the first brood between the two populations was observed, and organisms from the population I were on average larger than those of population $\mathrm{R}$, both in recently filed-collected and in fully acclimated females. These results indicate that differences in life-history traits registered between populations are not a result of directional life-cycle modifications to counteract reduced fitness in this heavy metal contaminated environment. Instead, they seem to be characteristics inherent to specific genotypes, which were positively selected in the stressful environment. Furthermore, the lower reproductive effort in the population $\mathrm{R}$ might have been a result of an isometric constraint of smaller animals having smaller brood chambers, rather than an adaptive response to heavy metal contamination by the population I. This hypothesis was corroborated by the correlation between length and reproductive output (neonates per female), showing that smaller animals released fewer neonates.

With the elimination of some lineages, it would be expected that population I would exhibit a lower bread in responses (measured as $\mathrm{CVs}$ ), especially because, as stated above, the most frequent lineages in each population exhibited significant differences in life-history patterns after acclimation. Furthermore, acclimated organisms from population $\mathrm{R}$ showed a sig- 


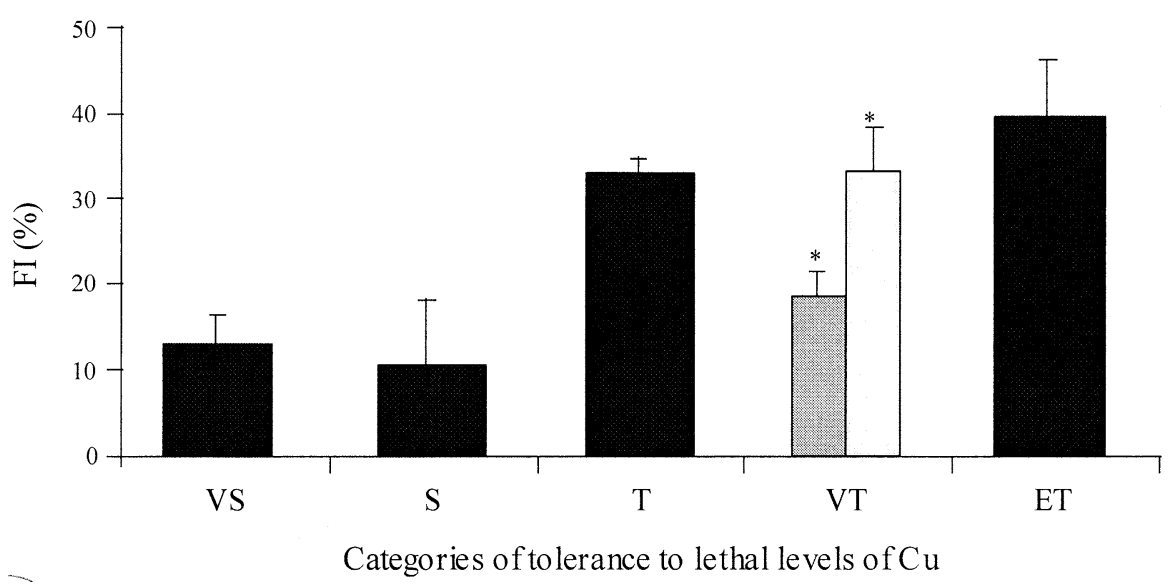

Fig. 5. Feeding inhibition (FI) (average + $\mathrm{SE})$ of tolerance categories of fully acclimated Daphnia longispina from both populations (heavy gray bars), and from populations R (light gray bars) and I (white bars). FI was significant in all comparisons $(p \leq$ $0.02)$. Asterisks represent significant differences $(p=0.01)$ between populations within the same category (VT). nificantly higher variability in reproduction and feeding responses. Nevertheless, in recently field-collected females, no significant differences were observed in response variability of released neonates or body length. Therefore, the absence of significant differences in CVs between nonacclimated populations point to the hypothesis that life-history patterns, in the field, are determined, not only genetically, but also by the environment. Thus, the remaining variability, measured after acclimation in laboratory, was determined genetically, and so the lower CVs of population I indicated the occurrence of genetic erosion (the elimination of the more sensitive lineages).

Theories on adaptive changes predict that the acquisition of tolerance to anthropogenic stress involves fitness costs (Hoffman and Parsons 1994). In the case of heavy metal tolerance, cost could be associated to an increase in energy expenditure with tolerance mechanisms. Furthermore, this increased investment in tolerance mechanisms could imply trade-offs between the benefits of adaptation and the costs incurred through the decreased energy expenditure in other processes (e.g., growth and reproduction). If tolerance mechanisms involve a less efficient metal uptake or utilization, essential micronutrient deficiency would occur in the absence of heavy metals (Hoffman and Parsons 1994). Several examples of trade-offs have been reported in the literature. For example, Postma et al. (1995) found that cadmium-tolerant populations of Chironomus riparius, reared in the absence of cadmium, showed a lower fitness, which was partially caused by zinc deficiency. Shirley and Sibly (1999) induced tolerance to cadmium in Drosophila melanogaster and observed that the acquisition of tolerance to cadmium increased the fitness in polluted environments, but only at the cost of reduced growth and reproduction in unpolluted environments.

In this study, evidence for the existence of trade-offs was not observed. Actually, under optimal conditions (clean water, food ad libitum, high temperature, no predator pressure), population I performed better than population $\mathrm{R}$, since, aside from similar individual relative investments on reproduction, fully acclimated organisms were on average larger and ingested more algae under optimal conditions. A higher number of juveniles per female and larger organisms were also observed in the recently field-collected females from population I (nonacclimated population from stressed environment). Thus, these results suggest no trade-offs, in the studied life-history traits of population I. Koehn and Bayne (1989) suggested that increased stress resistance might not always lead to trade-offs between optimal and stressful environments. They argued that stress resistance is associated with the efficiency of metabolic resources. Thus, organisms with a high level of efficiency may be able to maintain life-cycle traits through a wider range of environmental conditions.

\section{Tolerance to Sublethal Levels of Copper}

Finally, the fifth goal of this study was to determine if historical exposure to AMD contamination also resulted in genetically determined tolerance differences to sublethal levels between the two populations. This hypothesis was tackled through the comparison of feeding inhibition between populations ( $\mathrm{R}$ and I), within the same lethal tolerance category. No significant differences were found, except in category VT where, unexpectedly, lineages from population $\mathrm{R}$ ate more than those from population I. Therefore, historical exposure to AMD contamination conferred enhanced genetically determined tolerance to lethal levels of copper in population I but not at sublethal levels (i.e., no increased feeding inhibition), within categories similarly tolerant to lethality. These results are in agreement with conclusions reached by Baird et al. (1990) when compared lethal and sublethal responses of D. magna to cadmium and DCA. They stated that lethal responses are likely to be controlled by specific mechanisms while sublethal responses are likely to be controlled by general mechanisms, which, in turn, are likely to be closely associated with fitness, and thus, have low heritability, since they will be under continuous selection. Other authors also failed to find concordance in the ranking of genotypes by their tolerance to lethal and sublethal levels of toxicants. Barata et al. (2000) compared toxicity in tolerant and sensitive clones of D. magna exposed to lethal and sublethal levels of copper, and found that genotypes exhibited no concordance in tolerance between lethal and sublethal responses. They suggested that lethal responses are likely to be regulated by one or a few specific mechanisms, while sublethal responses, such as feeding behavior, are likely to depend on more than one general physiological mechanism (filtering, ingestion, gut physiology). Thus, it is unlikely that similar genes will 
regulate lethal and feeding responses, and, thus, a failure to find genotype concordance between lethal and sublethal responses is not unexpected.

\section{Conclusions}

In conclusion, D. longispina from population I evolved genetically-based tolerance to lethal levels of copper, which resulted from genetic erosion of the original founder population, specifically, the disappearance of the most sensitive lineages. The adaptation to the stressful environment did not involve directional life-cycle traits changes or fitness costs. The acquisition of tolerance to lethal levels was not associated with tolerance to sublethal levels, within categories similarly tolerant to lethality, since lineages with similar tolerance to lethal levels, from both populations, showed similar sublethal responses, or even an unexpected inversion (i.e., VT lineages from population I showed a lower tolerance in feeding responses than population $\mathrm{R})$.

The present study provided further evidence confirming the genetic erosion hypothesis, specifically, pollution is responsible for the loss of genetic diversity at the population level (van Straalen and Timmermans 2002). Furthermore, the methodology that was here developed contributes to the enlargement of available approaches to evaluate changes in the gene pool of natural populations due to contaminants. The relevancy of this contribution is emphasized by the fact that ecological risk assessments do not usually incorporate genetic diversity measurements, though genetic variation within species was one of the three pillars of biodiversity recognized in the Rio Convention of 1993 (van Straalen and Timmermans 2002).

Acknowledgments. This work was partially funded by Fundação para a Ciência e a Tecnologia-PRAXIS XI.

\section{References}

American Society for Testing and Materials (1994) Standard guide for conducting renewal life-cycle toxicity test with Daphnia magna. In: Annual Book of American Society of Testing and Materials Standards. E1193-94. American Society of Testing and Materials, Philadelphia, PA, USA

Baird DJ, Barber I, Calow P (1990) Clonal variation in general responses of Daphnia magna Straus to toxic stress. I. Chronic life-history effects. Funct Ecol 4:399-407

Baird DJ, Soares AMVM, Girling A, Barber MC, Calow P (1989) The long term maintenance of Daphnia magna Straus for use in ecotoxicity tests: Problems and prospects. In: Lokke H, Tyle H, Bro-Rasmussen F (eds) Proceedings of the First European Conference on Ecotoxicology. Lyngby, Denmark, pp 144-148

Barata C, Baird DJ (1998) Phenotypic plasticity and constancy of life-history traits in laboratory clones of Daphnia magna Straus: Effects on neonatal length. Funct Ecol 12:442-452

Barata C, Baird DJ, Miñarro A, Soares AMVM (2000) Do genotype responses always converge from lethal to non-lethal toxicant exposure levels? A hypothesis tested using laboratory Daphnia magna Straus clones. Environ Toxicol Chem 19:2314-2322

Bodar CWM, Van der Sluis I, van Montfort JCP, Voogt PA, Zandee
DI (1990) Cadmium resistance in Daphnia magna. Aquat Toxicol 16:33-40

Castro BB, Guilhermino L, Ribeiro R (2003) In situ bioassay chambers and procedures for assessment of sediment toxicity with Chironomus riparius. Environ Pollut 125:325-335

Donker MH, Zonneveld C, van Straalen NM (1993) Early reproduction and increased reproductive allocation in metal-adapted populations of the terrestrial isopod Porcellio scaber. Oecologia 96: 316-323

Falconer DS (1996) Introduction to quantitative genetics. Longman, London

Forbes VE, Calow P (1997) Responses of aquatic organisms to pollutant stress: Theoretical and practical implications. In: Bijlsma R, Loescchcke V (eds) Environmental stress, adaptation and evolution. Birkhäuser Verlag, Basel

Gad SC, Weil C (1992) Statistics for toxicologists. In: Hayes W (ed) Principles and methods of toxicology. Raven Press, New York

Groenendijk D, Kraak MHS, Admiraal W (1999) Efficient shedding of accumulated metals during metamorphosis in metal-adapted populations of the midge Chironomus riparius. Environ Toxicol Chem 18:1225-1231

Guillemaud T, Lenormand T, Bourguet D, Chevillon C, Pasteur N, Raymond M (1998) Evolution of resistance in Culex pipiens: Allele replacement and changing environment. Evolution 52:443453

Hoffmann AA, Parsons PA (1994) Evolutionary genetics and environmental stress. Oxford University Press, New York

Klerks PL, Weis JS (1987) Genetic adaptation to heavy metals in aquatic organisms: A review. Environ Pollut 45:173-205

Lam PKS (1999) Methods for distinguishing genetic and environmental variance in stress tolerance. Ecol Appl 9:449-455

Lopes I, Gonçalves F, Soares AMVM, Ribeiro R (1999a) Discriminating the ecotoxicity due to metals and to low $\mathrm{pH}$ in acid mine drainage. Environ Ecotoxicol Saf 44:207-214

Lopes I, Gonçalves F, Soares AMVM, Ribeiro R (1999b) Ecotoxicological tools in the remediation of acid mine drainage. Toxicol Environ Chem 70:441-460

Maltby L, Calow P, Pindar L (1987) Adaptation to acidification in aquatic invertebrates; speculation and preliminary observations. Annls Soc R Zool Belg 117:105-115

Macnair MR (1997) The evolution of plants in metal-contaminated environments. In: Bijlsma R, Loescchcke V (eds) Environmental stress, adaptation and evolution. Birkhäuser Verlag, Basel

Monni S, Salemaa M, Millar N (2000) The tolerance of Empetrum nigrum to copper and nickel. Environ Pollut 109:221-229

Nordal I, Haraldsen KB, Ergon A, Eriksen AB (1999) Copper resistance and genetic diversity in Lychnis alpina (Caryophylaceae) populations on mining sites. Folia Geobotanica 34:471-481

Pereira EG, Moura I, Costa JR, Mahony JD, Thomann RV (1995) The S. Domingos Mine: A study of heavy metals contamination in the water column and sediments of the Chança River basin by discharge from an ancient cupriferous pyrite mine (Portugal). Mar Freshwater Res 46:145-151

Pereira AMM, Soares AMVM, Gonçalves F, Ribeiro R (1999) Test chambers and test procedures for in situ toxicity testing with zooplankton. Environ Toxicol Chem 18:1956-1964

Pereira AMM, Soares AMVM, Gonçalves F, Ribeiro R (2000) Watercolumn, sediment, and in situ chronic bioassays with dadocerans. Environ Ecotoxicol Saf 47:27-38

Posthuma L, Verweij RA, Widianarko B, Zonneveld C (1993) Life-history patterns in metal-adapted Collembola. Oikos 67: 235-249

Postma JP, Mol S, Larsen H, Admiraal W (1995) Life-cycle changes and zinc shortage in cadmium-tolerant midges, Chironomus riparius (Diptera), reared in the absence of cadmium. Environ Toxicol Chem 14:117-122 
Reinecke SA, Prinsloo MW, Reinecke AJ (1999) Resistance of Eisenia fetida (Oligochaeta) to cadmium after long-term exposure. Ecotoxicol Environ Saf 42:75-80

Ribeiro R, Martins AMA, Correia JCA, Lopes I, Pereira A, Canteiro MHSF, Gonçalves F, Soares AMVM (1995) Vertebrados da zona de São Domingos (Baixo Alentejo). Ciênc Biol Ecol Syst 15: $33-47$

Shirley MDF, Sibly RM (1999) Genetic basis of a between-environment trade-off involving resistance to cadmium in Drosophila melanogaster. Evolution 53:826-836
Teschner M (1995) Effects of salinity on the life history and fitness of Daphnia magna: Variability within and between populations. Hydrobiologia 307:33-41

van Straalen NM (1994) Biodiversity of ecotoxicological responses in animals. Netherl J Zool 44:112-129

van Straalen NM, Timmermans MJTN (2002) Genetic variation in toxicant-stressed populations: An evaluation of the "genetic erosion" hypothesis. Human Ecol Risk Assess 8:983-1002

Zar JH (1996) Biostatistical analysis. Prentice-Hall International, Upper Saddle River, NJ 